Article

\title{
Utility of the Teslar Facial Massager for Skin Elasticity and the Mechanism of its Effects
}

\author{
Kazuhisa Maeda ${ }^{1,2, *(\mathbb{C})}$, Sakura Koizumi ${ }^{1}$, Taiga Sano ${ }^{1}$, Ayano Yoshimura ${ }^{2}$, Haruka Kiriyama ${ }^{2}$ \\ and Seina Mimura ${ }^{2}$ \\ 1 Bionics Program, Tokyo University of Technology Graduate School, Tokyo 192-0982, Japan; \\ b011410318@edu.teu.ac.jp (S.K.); b011413359@edu.teu.ac.jp (T.S.) \\ 2 School of Bioscience and Biotechnology, Tokyo University of Technology, Tokyo 192-0982, Japan; \\ b01142883e@edu.teu.ac.jp (A.Y.); b011507460@edu.teu.ac.jp (H.K.); b011523789@edu.teu.ac.jp (S.M.) \\ * Correspondence: kmaeda@stf.teu.ac.jp; Tel.: +81-42-6372442
}

Received: 1 July 2018; Accepted: 10 August 2018; Published: 14 August 2018

\begin{abstract}
The Teslar is a facial massager that emits a weak electric current, where users have reported a beneficial effect on skin elasticity with continued use. Accordingly, we conducted a clinical utility study and a comprehensive gene analysis, with cultured human fibroblasts to investigate the utility and mechanism of this treatment. In this clinical utility study, we found significant improvement in skin elasticity in Teslar treatments, compared to controls after two weeks of treatment. In cell experiments, we found that adenosine triphosphate synthesis and collagen contraction were promoted in fibroblasts cultured in type I collagen gel, following Teslar treatment. We considered that Teslar treatment exerted a structurally regenerative effect on the dermal matrix, based on the results of GeneChip ${ }^{\circledR}$ Expression Analysis. In particular, we demonstrated that Teslar treatment promotes type I collagen mRNA expression and fibulin-5/DANCE (Developmental arteries and neural crest EGF (epidermal growth factor)-like) mRNA expression and protein levels, which are reduced with aging. We also found increases in LTBP-3 (Latent TGF- $\beta$ binding protein-3) and CSPG4 (Chondroitin sulfate proteoglycan 4) mRNA expression levels. Based on these results, we considered that Teslar treatment promoted dermal regeneration and recovery of skin elasticity.
\end{abstract}

Keywords: Teslar; skin elasticity; adenosine triphosphate (ATP); fibulin-5/DANCE

\section{Introduction}

Skin cells have poor tensile strength and are vulnerable to pressure, and the surrounding extracellular matrix provides a strong, elastic tissue for support. The tissue is considerably strengthened by collagen fibers and glycosaminoglycans, but these elements alone cannot facilitate expansion and contraction. Dermal elasticity is conferred by elastic fibers, which are part of the extracellular matrix [1,2]. Elastic fiber turnover is very slow, similar to that for collagen fibers [3,4]. Consequently, they deteriorate with age, causing loss of dermal elasticity. This loss of dermal elasticity causes the skin to sag and lose its elasticity. Age-induced deterioration and elastic fiber breakdown render the skin unable to expand and contract, which is considered the direct cause of sagging and loss of elasticity. However, age is not the only cause of these effects; other factors involved in elastic fiber degradation include ultraviolet light-induced elastase (elastic fiber break down enzyme) expression, smoking-induced macrophage accumulation, and increases in elastase secretion. The fundamental solution for these issues involves reconstruction of elastic fibers.

The main body of an elastic fiber consists of filamentous bundles of elastin cross-linked at many locations; however, fibulin-5/DANCE (Developmental arteries and neural crest EGF-like), also plays a crucial role as the organizing component for fiber structure. Cross-linked, insoluble elastin has the 
specific, rubber-like properties of expandability and contractibility. Elastic fibers decrease with aging, preceded by an age-related decrease in fibulin-5 [5].

The Teslar is a facial massager that emits a weak electric current and can be used at home. It has been commercially available for more than 10 years. Teslar users reportedly believe that the device has the beneficial effect of promoting skin elasticity. Therefore, we sought to gather substantiating evidence on this effect by conducting a clinical utility study, a comprehensive gene analysis with cultured human fibroblasts, and fibulin-5/DANCE mRNA and protein analyses.

\section{Materials and Methods}

\subsection{Clinical Study}

\subsubsection{Study Subjects}

We enrolled 12 Japanese women, aged between 30 and 59 years, who had concerns regarding facial sagging and enlarged pores, with four women in each age decade. Based on the results of the preliminary tests, the number of subjects was set to $n=12$, with the control on one cheek and the Teslar treatment on the other cheek. We had a preliminary questionnaire, where the user assessed the improvement in skin elasticity and sagging pores after using Teslar for 4 weeks. Using these results, we planned a protocol to evaluate the product after 2 weeks and 4 weeks of use. The subjects were asked to apply the facial massager to one cheek, once daily, for four weeks. The assessors were blinded in this study and did not know which subjects were Teslar treatments and which subjects were controls. The subjects did not use other facial care devices for two weeks before initiation of the study, until completion of the study.

This study was approved by the ethics committee of our institution (E17BS-006), and written consent was obtained from the subjects after the purpose and details of the study had been explained to them. The study was conducted, between 16 October and 13 November 2017.

\subsubsection{Teslar Method and the Time of Use}

The Teslar used in this study was a commercially available device for home use (product name: Teslar; supplier: Nanostyle Inc., Tokyo, Japan). The Teslar was applied to one cheek after application of a specialized gel, once daily, for four weeks. We compared skin conditions on the relevant cheek (elasticity, pore parameters, and porphyrin level), between Teslar treatments and controls (subjects who had applied the gel only and did not use the Teslar device), to elucidate differences between the two treatments in a scientific evaluation involving measurements with specialized devices. The Teslar was applied in 30-s sessions.

Composition of the specialized gel:

Water, glycerin, ethanol, dimethicone, carbomer, sodium hydroxide, acrylates/C10-30 alkyl acrylate crosspolymer, ethylenediaminetetraacetic acid disodium salt, methylparaben, xanthan gum, dipotassium glycyrrhizinate, and tocopherol.

\subsubsection{Skin Evaluation Method}

The following parameters were measured for both cheeks, before Teslar or control treatments, and at two and four weeks after treatment initiation: Elasticity, pore area, pore aspect ratio, and porphyrin level. Measurements were obtained in a temperature- and humidity-controlled room. The mean temperature and humidity [ \pm standard deviation (SD)], were $25.0 \pm 0.6^{\circ} \mathrm{C}$ and $37.5 \pm 0.5 \%$ before treatment (16 October 2017), $24.7 \pm 0.3{ }^{\circ} \mathrm{C}$ and $37.1 \pm 0.5 \%$ after two weeks of treatment (30 October 2017), and $24.8 \pm 0.6^{\circ} \mathrm{C}$ and $37.2 \pm 0.7 \%$ after four weeks of treatment, respectively (13 November 2017).

The temperature and humidity in the measurement room did not differ between the three measurement days. Elasticity was measured with a Cutometer ${ }^{\circledR}$ MPA580 (Courage+Khazaka Electronic 
GmbH, Köln, Germany). The pore area and aspect ratio were measured with a Visioscan ${ }^{\circledR}$ VC98 USB device (Courage+Khazaka Electronic GmbH, Köln, Germany) and a Pore analysis software KN-SO (Integral Corporation, Tokyo, Japan). The porphyrin level was measured using VISIA ${ }^{\circledR}$ (Canfield Scientific, Inc., Parsippany, NJ, USA).

\subsection{Comprehensive Gene Analysis}

A six-well plate was placed on ice, and $200 \mu \mathrm{L}$ of (glutamine-supplemented) 10-fold-diluted minimum essential medium, $200 \mu \mathrm{L}$ of fetal bovine serum (FBS), $1400 \mu \mathrm{L}$ of native collagen acidic solution (3 mg/mL; AIC-30, Koken Co., Ltd., Tokyo, Japan), $40 \mu \mathrm{L}$ of $1 \mathrm{~mol} / \mathrm{L}$ sodium bicarbonate solution, and $160 \mu \mathrm{L}$ of human fibroblast preparation (at 30,000 cells $/ \mathrm{mL}$; National Institutes of Biomedical Innovation, Health and Nutrition, Osaka, Japan) were added to the plate in that order. The plate was incubated for $1 \mathrm{~h}$ at $37^{\circ} \mathrm{C}$, with gentle shaking to form a gel; then, $2 \mathrm{~mL}$ of Dulbecco's Modified Eagle's medium (supplemented with 10\% FBS) was added to culture the cells for one day. The culture medium was discarded, and then the Teslar facial massager was applied to different sites, in five 3-s cycles, followed by 1-s rest intervals, for a total of $20 \mathrm{~s}$. Three plates were prepared using this procedure, and the cellular gel on each plate was cultured for 3 and $48 \mathrm{~h}$. Total RNA was extracted at each time point with an RNA extraction kit (RNeasy Mini Kit, Qiagen GmbH, Hilden, Germany), and the results were aggregated for each set of six wells. Analysis with an Affymetrix GeneChip ${ }^{\circledR}$ Expression Array was commissioned to Takara Bio Inc. (Siga, Japan).

\subsection{Measurement of Cellular Adenosine Triphosphate}

Cells were cultured for 2 days, and $2-\mu \mathrm{L}$ aliquots of adenosine triphosphate (ATP) analysis reagent were then added. Each plate was left to stand in a Multi-Detection Microplate Reader (POWERSCAN HT, BioTek Instruments Inc., Winooski, VT, USA), with the temperature set at $23^{\circ} \mathrm{C}$ for $10 \mathrm{~min}$, and luminescence was then measured. In another procedure, $200-\mu \mathrm{L}$ aliquots of Cell Counting Kit- 8 reagent (Dojindo laboratories, Kumamoto, Japan) were added to the wells, and luminescence was measured at $450 \mathrm{~nm}$ immediately, and $2 \mathrm{~h}$ after reagent addition. The $2 \mathrm{~h}$ change $(\Delta)$ in luminescence was regarded as the quantity of cells for evaluation. ATP-induced luminescence was divided by the quantity of cells to obtain the amount of ATP per cell. The experiment was performed in triplicate.

\subsection{Teslar Effects on Fibulin-5/DANCE, Fibrillin 1, Collagen 5A, and Collagen $12 \mathrm{~A}$ mRNA in Cultured Human Fibroblasts}

After removal of the culture medium, the Teslar facial massager was applied to different sites in the cellular gel at an intensity grade of +3 , in five 3-s cycles, with 1-s rest intervals, for a total of $15 \mathrm{~s}$. Three plates were prepared in this way. The cellular gel on each plate was cultured for $48 \mathrm{~h}$, and total RNA was extracted with an RNA extraction kit. mRNA expression was quantified for fibulin-5/DANCE, fibrillin 1 , collagen $5 \mathrm{~A}$, collagen $12 \mathrm{~A}$, and $\beta$-actin with a real-time polymerase chain reaction, using One Step SYBR Prime Script RT-PCR Kit II (Takara Bio Inc.) in a real-time PCR device (ABI PRISM 7900HT, Applied Biosystems Co., Ltd., Waltham, MA, USA). The primers used were purchased from Qiagen. This experiment was conducted in triplicate.

\subsection{Fluorescent Antibody Staining for Fibulin-5/DANCE and Fibrillin 1 in Cultured Human Fibroblasts}

Human fibroblasts were cultured in a collagen gel, and the Teslar facial massager was applied to the cultured fibroblasts at different sites in the cellular gel at an intensity grade of +3 , for five $3 \mathrm{~s}$ cycles, with $1 \mathrm{~s}$ rest intervals, for a total of $15 \mathrm{~s}$. The fibroblasts were then cultured for 5 days and then fixed in $4 \%$ paraformaldehyde phosphate buffer solution. Specimens were prepared by frozen sectioning and then subjected to immunohistochemical staining under a fluorescence microscope. To perform fibulin-5/DANCE protein imaging, specimens were stained with anti-fibulin-5/DANCE polyclonal antibody (Cloud-Clone Corp., Katy, TX, USA), goat anti-rabbit IgG $(\mathrm{H}+\mathrm{L})$ secondary antibody, and 
Alexa Fluor ${ }^{\circledR} 568$ (Thermo Fisher Scientific Inc., Waltham, MA, USA). The nuclei were stained with DAPI (4,6-diamidino-2-phenylindole).

\subsection{Fibulin-5/DANCE Western Blot Analysis in Cultured Human Fibroblasts}

Human fibroblasts were cultured in collagen gel, and the Teslar facial massager was applied to different sites in the cellular gel at intensity grades of $+1,+2$, and +3 , in five 3 s cycles, with $1 \mathrm{~s}$ rest intervals, for a total of $15 \mathrm{~s}$. The treated fibroblast gel was cultured for 5 days and then subjected to protein extraction. Proteins were separated using sodium dodecyl sulfate polyacrylamide gel electrophoresis and transferred to an Immobilon ${ }^{\circledR}$-PSQ membrane (Merck KGaA, Darmstadt, Germany). Staining was then performed with an anti-fibulin-5/DANCE monoclonal antibody (Proteintech Group Inc., Rosemont, IL, USA), followed by an HRP (Horseradish peroxidase) -conjugated anti-mouse IgG (GE Healthcare UK Ltd., Amersham Place, Buckinghamshire, England). Chemiluminescence detection was performed with ECL Prime Western Blotting Detection Reagent (GE Healthcare UK Ltd.), and the specimens were subjected to fibulin-5/DANCE protein imaging with a LuminoGraph I system (ATTO Corp., Tokyo, Japan). The specimens were then normalized using an anti- $\beta$-actin mouse monoclonal antibody (Proteintech Group Inc., Rosemont, IL, USA). Images were digitalized with ImageJ 1.46r analysis software.

\subsection{Statistical Analysis}

In the clinical utility study, each parameter and the change $(\Delta)$ in each parameter was statistically analyzed using a paired $t$-test (two-tailed). Two-tailed risk ratios less than $5 \%$ were regarded as representative of statistically significant differences at $p<0.05,0.01$, and 0.001 , and $p<0.1$ was regarded as indicative of a tendency to differ.

In the cell tests, each parameter was statistically analyzed using an unpaired $t$-test (two-tailed). Two-tailed risk ratios less than $5 \%$ were regarded as representative of statistically significant differences at $p<0.05,0.01$, and 0.001 , and $p<0.1$ was regarded as indicative of a tendency to differ.

\section{Results}

\subsection{Clinical Study}

\subsubsection{Study Subjects}

The analysis set included women who were not subject to restrictions or treatment discontinuation during the study, and who did not fulfill the analysis exclusion criteria. The analysis subjects were 24 Japanese women, aged between 30 and 56 years: 12 subjects were controls (gel treatment only), and 12 subjects were Teslar treatments. The mean age $( \pm$ SD) of the subjects was $44.6( \pm 9.9)$ years. There were no side effects after 4 weeks of use.

\subsubsection{Skin Elasticity (R7)}

The cheek elasticity measurement (R7) results, for the controls and Teslar treatments are presented in Figure 1. Elasticity was evaluated relative to the pretreatment value. Among the controls, cheek elasticity did not significantly differ from the pretreatment value after two or four weeks of treatment. Among the Teslar treatments, cheek elasticity had significantly increased from the pretreatment value after two weeks and four weeks of treatment. Changes in the cheek elasticity, were compared between the controls and Teslar treatments. The change in the cheek elasticity had increased significantly in the Teslar treatments compared to that in the controls, after two weeks of treatment. After four weeks of treatment, the change in the cheek elasticity was smaller in the Teslar treatments than that in the controls, with no significance, but had a tendency to differ between the two treatment groups. Given individual differences were large, the right cheek and left cheek values for each individual were carried out using a corresponding paired $t$-test (Figure 1a), and the difference $(\Delta)$ before and after treatment for 
each individual was assessed using a corresponding paired $t$-test (Figure $1 \mathrm{~b}$ ). The standard deviation was large, but significant differences and trends were obtained.

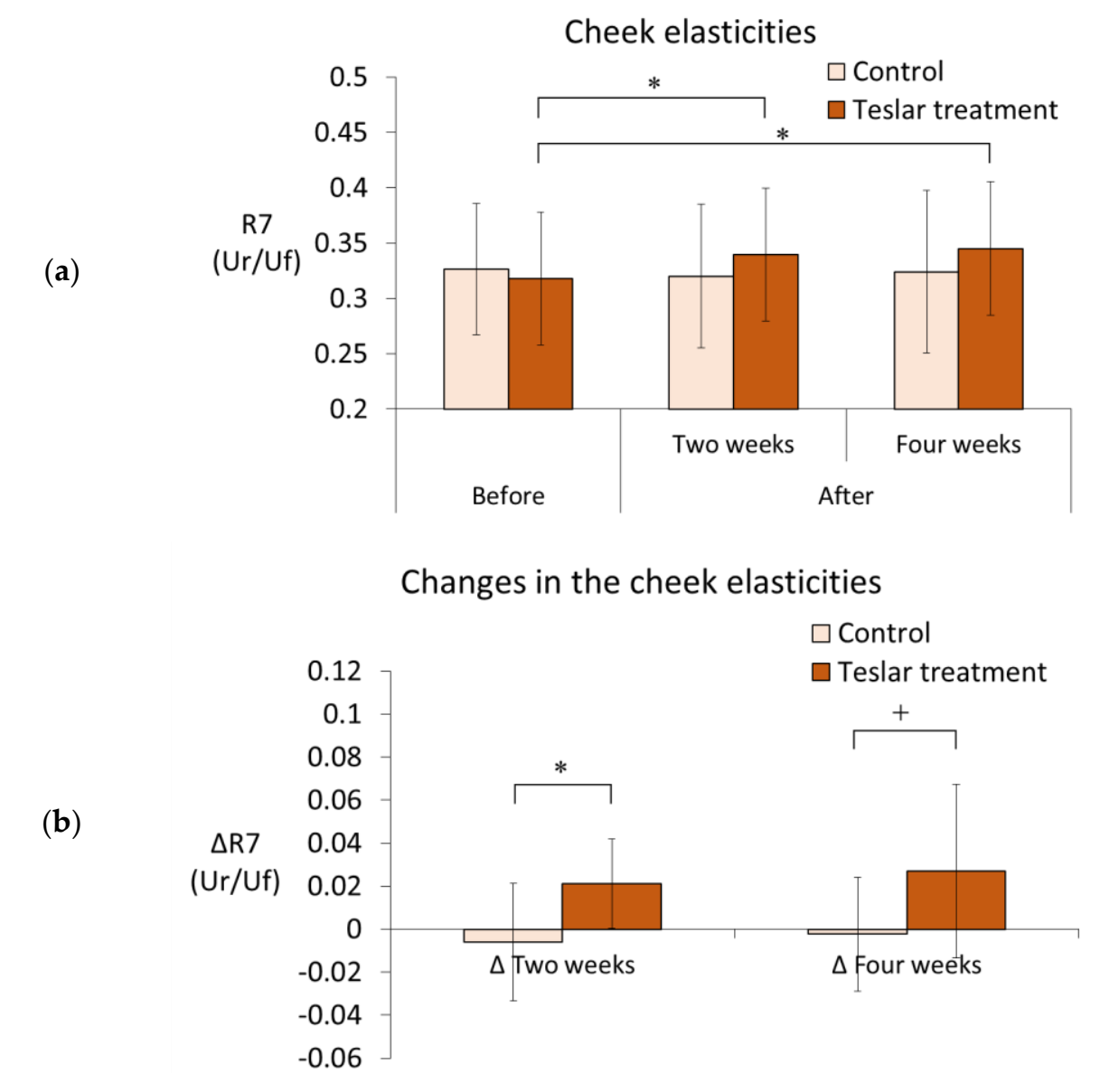

Figure 1. Cheek elasticities and changes in the cheek elasticities-Controls vs. Teslar treatments. (a) Cheek elasticities (R7) and (b) changes in the cheek elasticities $(\Delta R 7)$. The results are expressed as the mean \pm standard deviation of twelve experiments. ${ }^{*} p<0.05,+p<0.1$.

\subsubsection{Pore Area and Aspect Ratio}

The cheek pore areas of the controls and Teslar treatments, are presented in Figure 2a,b. The cheek pore area was evaluated relative to the pretreatment value. The cheek pore area did not significantly differ from the pretreatment value after two weeks of treatment, in either the controls or the Teslar treatments. The cheek pore area tended to be greater than the pretreatment value in the controls, but it did not significantly differ from the pretreatment value in the Teslar treatments after four weeks of treatment. Changes in the cheek pore area were compared, between the controls and Teslar treatments. The change in the cheek pore area was smaller in the Teslar treatments than that in the controls, with no significance, but had a tendency to differ between the two treatment groups after four weeks of treatment.

The pore aspect ratios of the controls and Teslar treatments, are presented in Figure 2c,d. The pore aspect ratio was evaluated relative to the pretreatment value. The cheek pore aspect ratio did not significantly differ from the pretreatment value after two weeks of treatment, in either the controls or the Teslar treatments. The cheek pore aspect ratio tended to differ between the controls and Teslar treatments after four weeks of treatment. Changes in the cheek pore aspect ratio were compared between the controls and Teslar treatments. The change in the cheek pore aspect ratio was smaller in the Teslar treatments than that in the controls, with no significance, but had a tendency to differ between the two treatment groups after four weeks of treatment. 
(a)

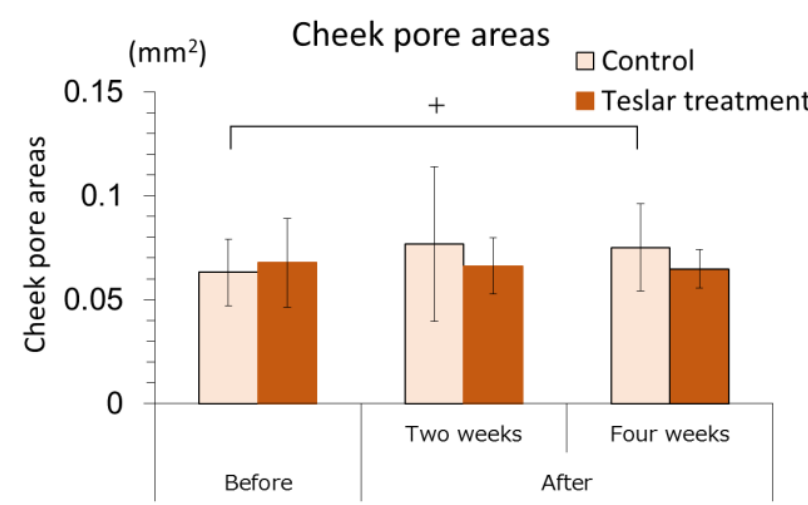

(b)

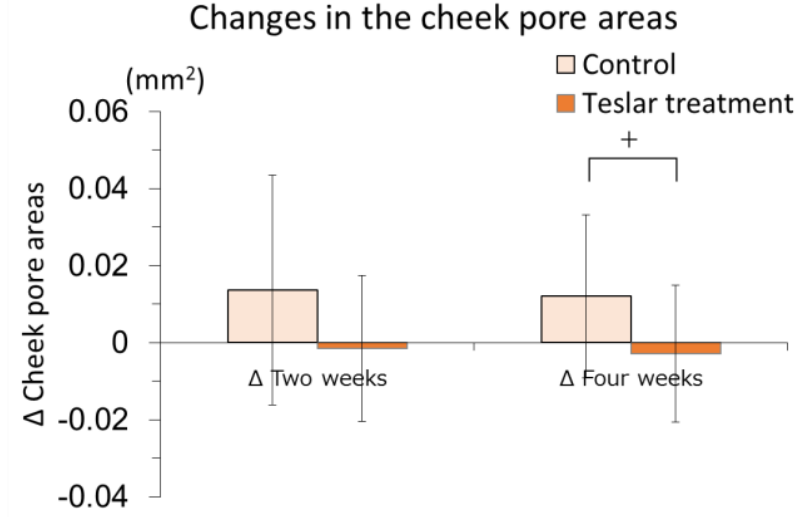

Cheek pore aspect ratios

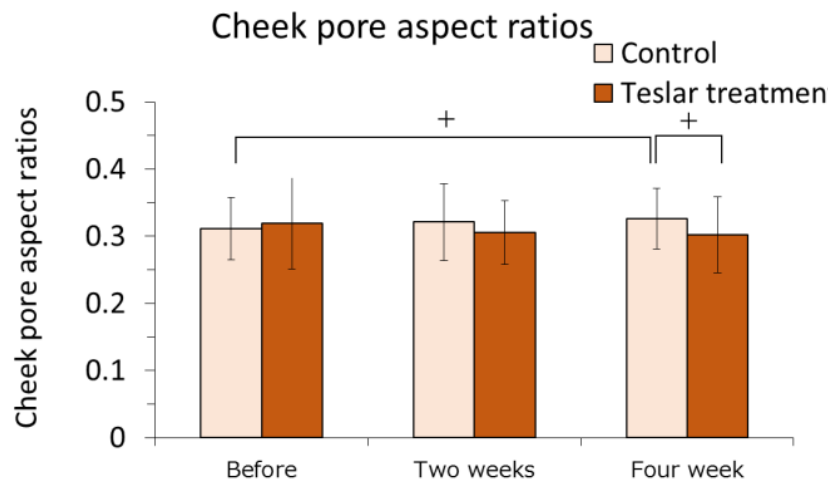

(d)

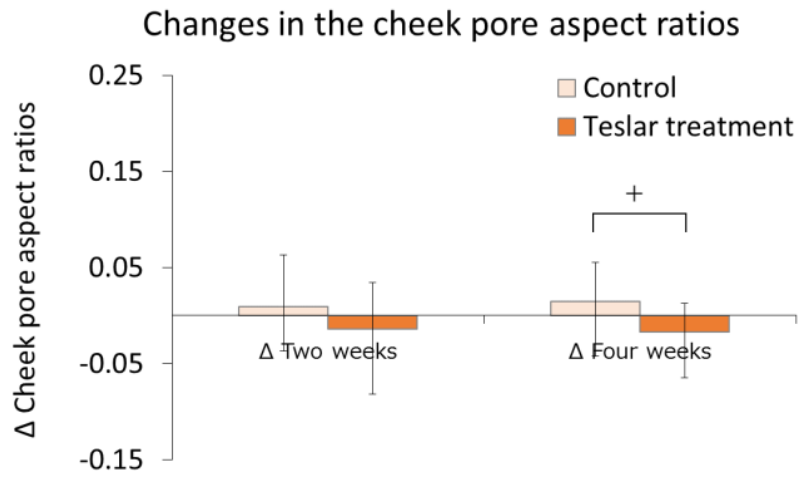

Figure 2. Cheek pore areas, changes in cheek pore areas, cheek pore aspect ratios and changes in the cheek pore aspect ratios-Controls vs. Teslar treatments. (a) Cheek pore areas; (b) changes in cheek pore areas; (c) cheek pore aspect ratios and (d) changes in the cheek pore aspect ratios. The results are expressed as the mean \pm standard deviation of twelve experiments. $+p<0.1$. 


\subsubsection{Porphyrin Analysis}

The left and right sides of each subject's face were imaged with the VISIA system, and the relative change in the porphyrin level was determined within a selected area of the cheek using image analysis software. The results are presented in Figure 3.

The porphyrin level was evaluated relative to the pretreatment level. Among the Teslar treatments, the cheek porphyrin level had significantly decreased compared to the pretreatment level after four weeks of treatment and tended to differ from the pretreatment level, after two weeks of treatment. Among the controls, the cheek porphyrin level did not differ significantly but tended to differ compared to the pretreatment level after two or four weeks of treatment. The Teslar and control treatments, yielded an evident reduction in porphyrin levels after four weeks.

Changes in the porphyrin level were compared, between the controls and Teslar treatments. No significant difference was noted between the treatment groups after two or four weeks of treatment.

(a)
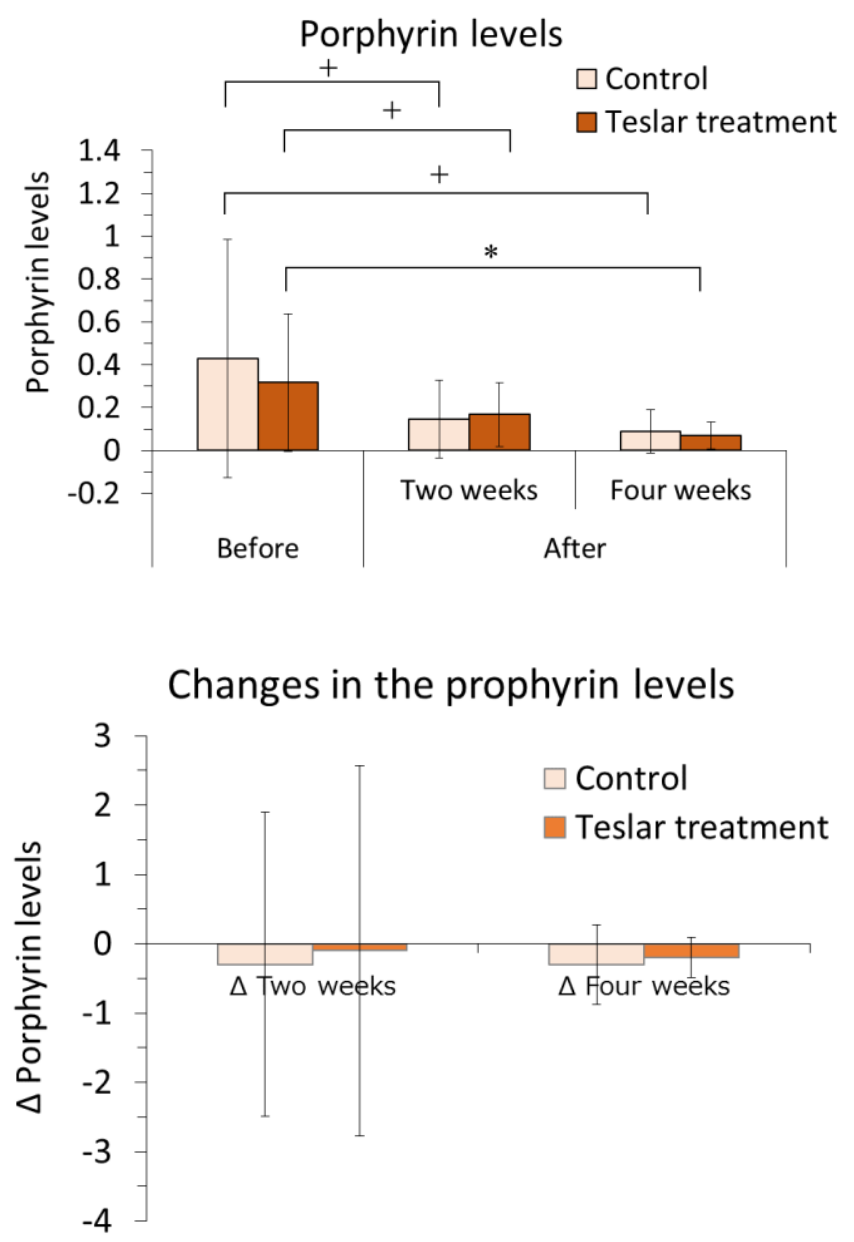

Figure 3. Cheek porphyrin levels and changes in the cheek porphyrin levels-Controls vs. Teslar treatments. (a) Cheek porphyrin levels and (b) changes in the cheek porphyrin levels. The results are expressed as the mean \pm standard deviation of twelve experiments. ${ }^{*} p<0.05,+p<0.1$.

\subsection{Comprehensive Gene Analysis}

We targeted genes related to ATP synthesis, growth factors, chemokines, transforming growth factor- $\beta$ (TGF- $\beta$ ), matrix metalloproteinases, integrin, fibronectin, chondroitin sulfate, fibrillin, fibulin, collagen, and elastin for investigation. Each gene with a scale signal of 400 or greater, was compared between the control and Teslar treatments. Genes with a greater change ratio at $3 \mathrm{~h}$ and/or $48 \mathrm{~h}$ after Teslar treatment, are presented in Table 1. 
Table 1. Fold increase of the gene expressions at 3 and $48 \mathrm{~h}$ after Teslar treatment relative to the control in collagen gel-cultured fibroblasts.

\begin{tabular}{|c|c|c|c|c|c|c|c|c|c|c|c|}
\hline Classification & Gene Symbol & $3 \mathrm{~h}$ & $p$ & $48 \mathrm{~h}$ & $p$ & Classification & Gene Symbol & $3 \mathrm{~h}$ & $p$ & $48 \mathrm{~h}$ & $p$ \\
\hline \multirow{2}{*}{ ATP } & АТР5J & 1.51 & $* *$ & 1.93 & $* *$ & \multirow{2}{*}{ CS } & CHST12 & 1.48 & $* *$ & 1.71 & ** \\
\hline & ATP6 & 1.59 & * & 1.68 & * & & CSPG4 & 2.37 & * & 1.72 & * \\
\hline GF & VEGFB & 1.47 & $* *$ & 2.13 & $* *$ & FBN & FBN1 & 1.56 & $* *$ & 1.58 & $* *$ \\
\hline Chemokine & CCL2 & 1.62 & ** & 3.45 & ** & \multirow{4}{*}{ FBLN } & FBLN1 & 1.39 & N.S. & 1.71 & ** \\
\hline \multirow{7}{*}{ TGF- $\beta$} & TGFBR3 & 1.45 & $* *$ & 0.70 & N.S. & & FBLN2 & 1.24 & N.S. & 1.85 & ** \\
\hline & LTBP1 & 1.43 & $* *$ & 0.93 & N.S. & & FBLN5 & 1.28 & N.S. & 1.60 & $* *$ \\
\hline & LTBP3 & 1.57 & $* *$ & 2.45 & $* *$ & & FBLN7 & 1.26 & N.S. & 1.76 & $* *$ \\
\hline & LTBP2 & 1.31 & N.S. & 1.74 & $* *$ & \multirow{10}{*}{ Collagen } & PLOD3 & 1.14 & N.S. & 1.58 & ** \\
\hline & TGFBI & 1.48 & N.S. & 1.55 & $* *$ & & PCOLCE & 1.10 & N.S. & 1.62 & ** \\
\hline & TGFBRAP1 & 1.45 & N.S. & 1.81 & ** & & COLGALT1 & 0.88 & N.S. & 1.87 & * \\
\hline & TGFB1I1 & 1.26 & N.S. & 1.57 & $* *$ & & SERPINH1 & 1.30 & N.S. & 1.59 & $* *$ \\
\hline \multirow{2}{*}{ MMP } & MMP11 & 1.35 & N.S. & 2.27 & $* *$ & & COL1A2 & 1.54 & N.S. & 1.68 & $* *$ \\
\hline & MMP14 & 1.24 & $* *$ & 2.28 & $* *$ & & COL5A1 & 1.05 & N.S. & 2.03 & ** \\
\hline \multirow{2}{*}{ Integrin } & ITGB1 & 1.54 & $*$ & 1.43 & N.S. & & COL7A1 & 1.07 & N.S. & 1.86 & $* *$ \\
\hline & ITGB2 & 1.19 & N.S. & 1.59 & $* *$ & & COL8A2 & 1.23 & N.S. & 1.63 & ** \\
\hline \multirow{4}{*}{ FN } & FN1 & 1.59 & $* *$ & 1.59 & $*$ & & COL12A1 & 1.29 & N.S. & 1.82 & ** \\
\hline & FNDC3B & 1.65 & $* *$ & 1.26 & N.S. & & COL15A1 & 1.24 & N.S. & 1.58 & $* *$ \\
\hline & FLRT2 & 1.60 & $* *$ & 1.15 & N.S. & \multirow{2}{*}{ Elastin } & EMILIN1 & 1.06 & N.S. & 2.04 & * \\
\hline & & & & & & & ELN & 1.03 & N.S. & 1.89 & $*$ \\
\hline
\end{tabular}

In this comprehensive gene analysis, Teslar-treated cells showed a greater ATP synthesis-related, growth factor-related, and chemokine-related gene expression compared to the controls from $3 \mathrm{~h}$ after treatment (ATP synthesis-related genes: ATP synthase-coupling factor 6, mitochondrial and ATP synthase subunit a; growth factor-related genes: vascular endothelial growth factor B; chemokine-related genes: $\mathrm{C}-\mathrm{C}$ motif chemokine 2, monocyte chemoattractant protein 1 (MCP-1)).

The results for the TGF- $\beta$ genes were as follows: Teslar-treated cells showed increased transforming growth factor beta receptor type 3 (TGFBR3) and latent-transforming growth factor beta-binding protein (LTBP) 1 expression at $3 \mathrm{~h}$ after treatment, increased LTBP3 expression at $3 \mathrm{~h}$ after treatment, and increased TGF- $\beta 1$ and matrix metalloproteinase-14 (MMP-14) expression at $48 \mathrm{~h}$ after treatment.

Teslar-treated cells, also showed increased fibronectin and chondroitin sulfate formation-related gene expression at $3 \mathrm{~h}$ after treatment. In contrast, Teslar-treated cells showed increased expression of the following genes at $48 \mathrm{~h}$ after treatment: Lysyl hydroxylase 3 (a procollagen production-related gene), serpin peptidase inhibitor (collagen fiber formation-related gene), type I collagen fiber-related gene, type V collagen fiber-related gene, type XII collagen fiber-related gene, type XV collagen fiber-related gene [in the order of alpha-2(I) chain, alpha-1(V) chain, alpha-1(XII) chain, and alpha-1(XV) chain], elastin and elastin microfibril interface-located protein 1 (elastic fiber formation-related genes), and fibulin-5/DANCE (required for elastic fiber structure).

The data were expressed as the fold increase of the gene expressions at 3 and $48 \mathrm{~h}$, after Teslar treatment relative to the control. Statistically significant differences, between the values at 3 and $48 \mathrm{~h}$ after Teslar treatment and the value of the control are shown. ${ }^{*} p<0.05$ vs. Control, ** $p<0.01$ vs. Control, N.S., no significance. Protein names: ATP5J, ATP synthase-coupling factor 6, mitochondrial; ATP6, ATP synthase subunit a; VEGFB (Vascular endothelial growth factor B); CCL2, C-C motif chemokine 2, Monocyte chemoattractant protein 1; TGFBR3, Transforming growth factor beta receptor type 3; LTBP1, Latent-transforming growth factor beta-binding protein 1; LTBP3, Latent-transforming growth factor beta-binding protein 3; LTBP2, Latent-transforming growth factor beta-binding protein 2; TGFBI, Transforming growth factor, beta 1; TGFBRAP1, Transforming growth factor-beta receptor-associated protein 1; TGFB1I1, Transforming growth factor beta-1-induced transcript 1 protein; MMP11, Stromelysin-3; MMP14, Matrix metalloproteinase-14; 
ITGB1, Integrin beta-1; ITGB2, Integrin beta-2; FN1, Fibronectin; FNDC3B, Fibronectin type III domain-containing protein 3B; FLRT2, Leucine-rich repeat transmembrane protein; CHST12, Carbohydrate sulfotransferase 12 (Chondroitin 4-O-sulfotransferase 2); CSPG4, Chondroitin sulfate proteoglycan 4; FBN1, Fibrillin 1; FBLN1, Fibulin-1; FBLN2, Fibulin-2; FBLN5, Fibulin-5; FBLN7, Fibulin-7; PLOD3, Procollagen-lysine,2-oxoglutarate 5-dioxygenase 3 (Lysyl hydroxylase 3); PCOLCE, Procollagen C-endopeptidase enhancer 1; COLGALT1, Procollagen galactosyltransferase 1; SERPINH1, Serpin peptidase inhibitor; COL1A2, Collagen alpha-2(I) chain; COL5A1, Collagen alpha-1(V) chain; COL7A1, Collagen alpha-1(VII) chain; COL8A2, Collagen alpha-2(VIII) chain; COL12A1, Collagen alpha-1(XII) chain; COL15A1, Collagen alpha-1(XV) chain; EMILIN1, Elastin microfibril interface-located protein 1; and ELN, Elastin.

\subsection{Measurement of Cellular ATP Levels}

The ATP level per cell was quantified for controls (untreated human fibroblasts) and Teslar-treated human fibroblasts after 2 days of culture, and the results are presented in Figure 4 . Teslar-treated human fibroblasts, showed a significantly higher ATP level per cell compared to untreated controls.

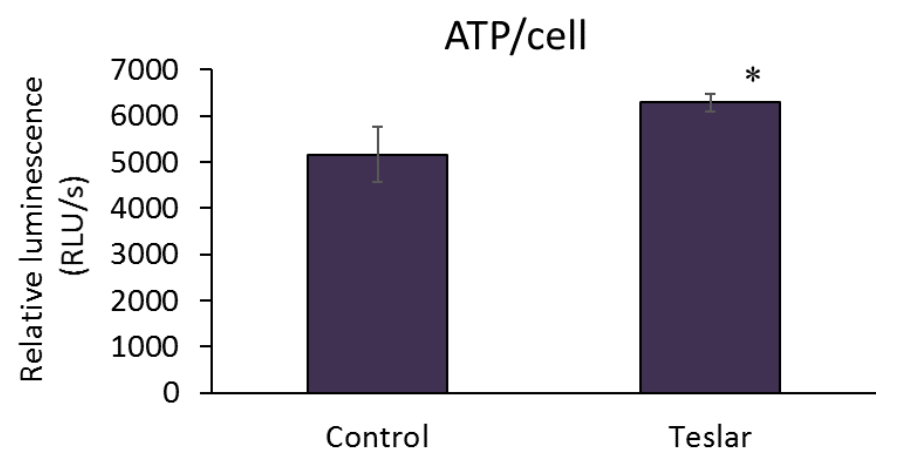

Figure 4. Teslar effect on cellular ATP levels in collagen gel-cultured human fibroblasts. The results are expressed as the mean \pm standard deviation of three experiments. ${ }^{*} p<0.05$ vs. Control.

\subsection{Teslar Effect on Fibulin-5/DANCE, Fibrillin 1, Collagen 5A, and Collagen 12A mRNA}

Teslar-treated cells, showed significantly increased levels of fibulin-5/DANCE mRNA relative to untreated controls (Figure 5). However, Teslar-treated cells showed no significant increase, but tended to differ compared to the controls in the levels of mRNA in fibrillin 1, collagen 5A, and collagen 12A (Figure 5).

(a)

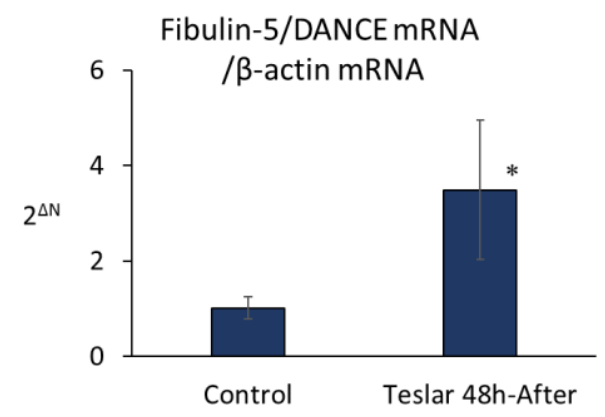

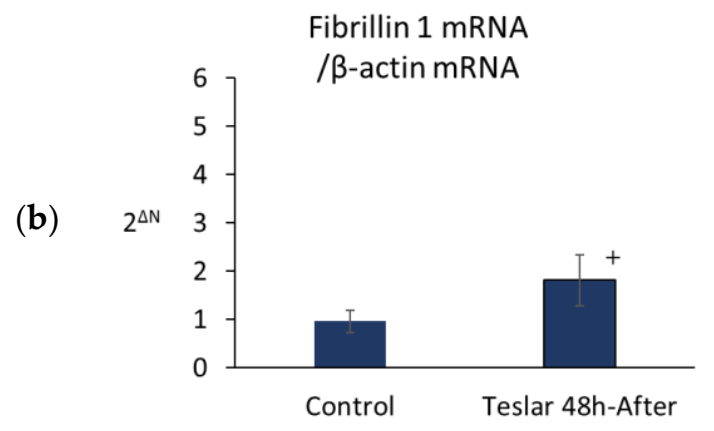

Figure 5. Cont. 

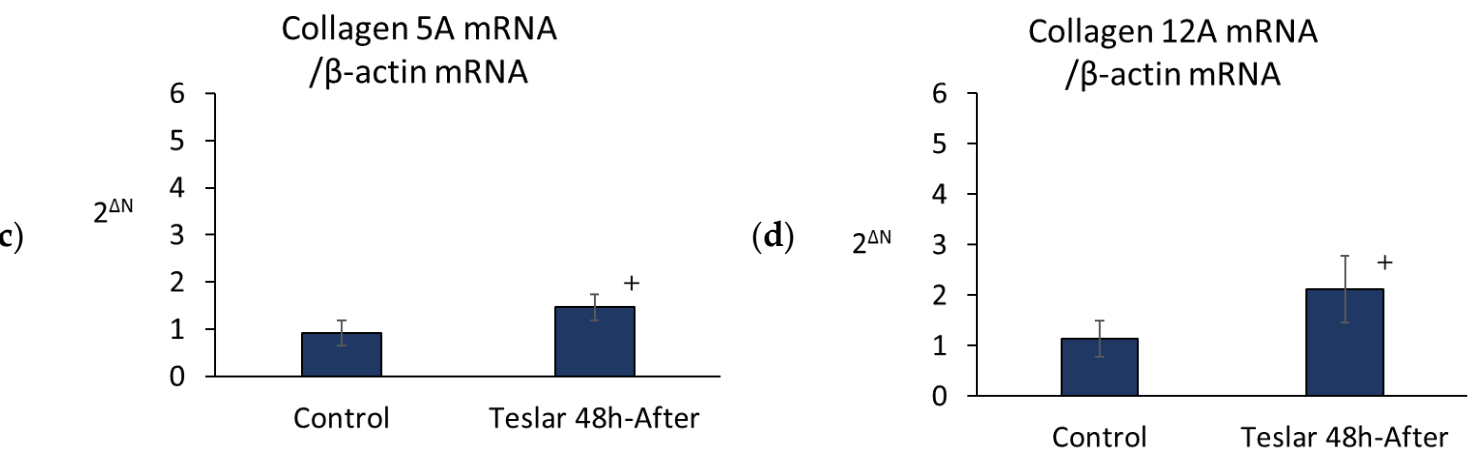

Figure 5. Teslar effect on fibulin-5/DANCE, fibrillin 1, collagen 5A, and collagen 12A mRNA in collagen gel-cultured human fibroblasts. (a) fibulin-5/DANCE; (b) fibrillin 1; (c) collagen 5A and (d) collagen 12A. The results are expressed as the mean \pm standard deviation of three experiments. * $p<0.05$ vs. Control, $+p<0.1$ vs. Control.

\subsection{Fluorescent Antibody Staining of Cultured Human Fibroblasts for Fibulin-5/DANCE}

The anti-fibulin-5/DANCE antibody reactive protein (red staining), was observed fibrously around the position of DAPI in the right figure (Teslar-treated collagen gel), compared with the left figure (control) in the extracellular matrix of the collagen gels. In the left figure (control), the anti-fibulin-5 antibody reactive protein (red staining), was observed in cells internally and in the periphery of the fibroblast, without being stained fibrously (Figure 6).

(a)

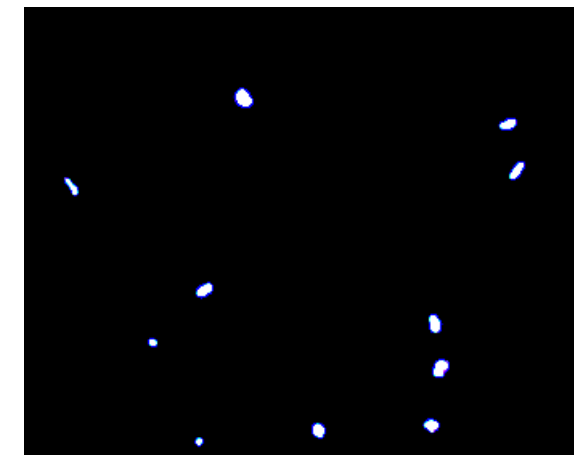

Control

DAPI staining

Anti-fibulin-5/DANCE antibody staining

(b)

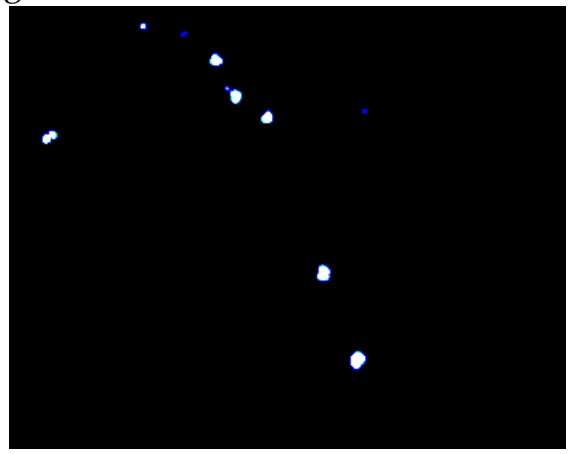

Teslar

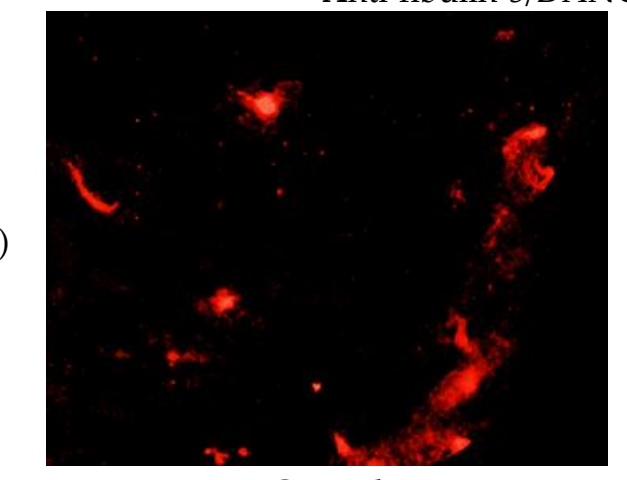

Control (d)

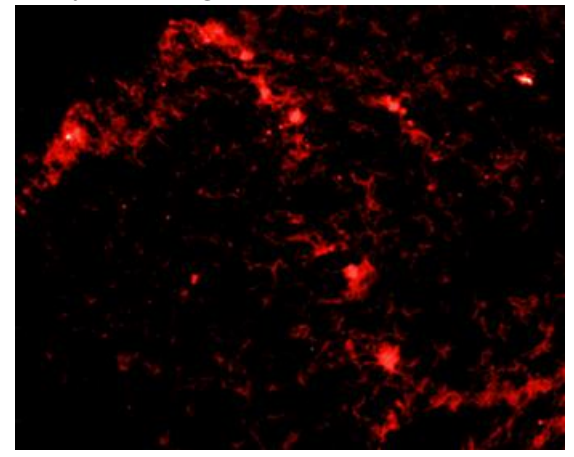

Teslar

Figure 6. Teslar effect on fibulin-5/DANCE protein in collagen gel-cultured human fibroblasts. (upper) DAPI staining of (a) control and (b) Teslar treatment collagen gel-cultured human fibroblasts, and (bottom) anti-fibulin-5/DANCE antibody staining of (c) control and (d) Teslar treatment collagen gel-cultured human fibroblasts. 


\subsection{Western Blotting for Fibulin-5/DANCE in Cultured Human Fibroblasts}

Protein binding of anti-fibulin-5/DANCE antibody was increased by treatment of Teslar in an intensity dependent manner, in collagen gel-cultured human fibroblasts. The increases at intensity grades +2 and +3 , were significant compared with the control (Figure 7).

\section{Control Teslar treatment}

$$
+1+2+3
$$

(a)

\section{Fibulin-5/DANCE}

$\beta$-actin

(b)

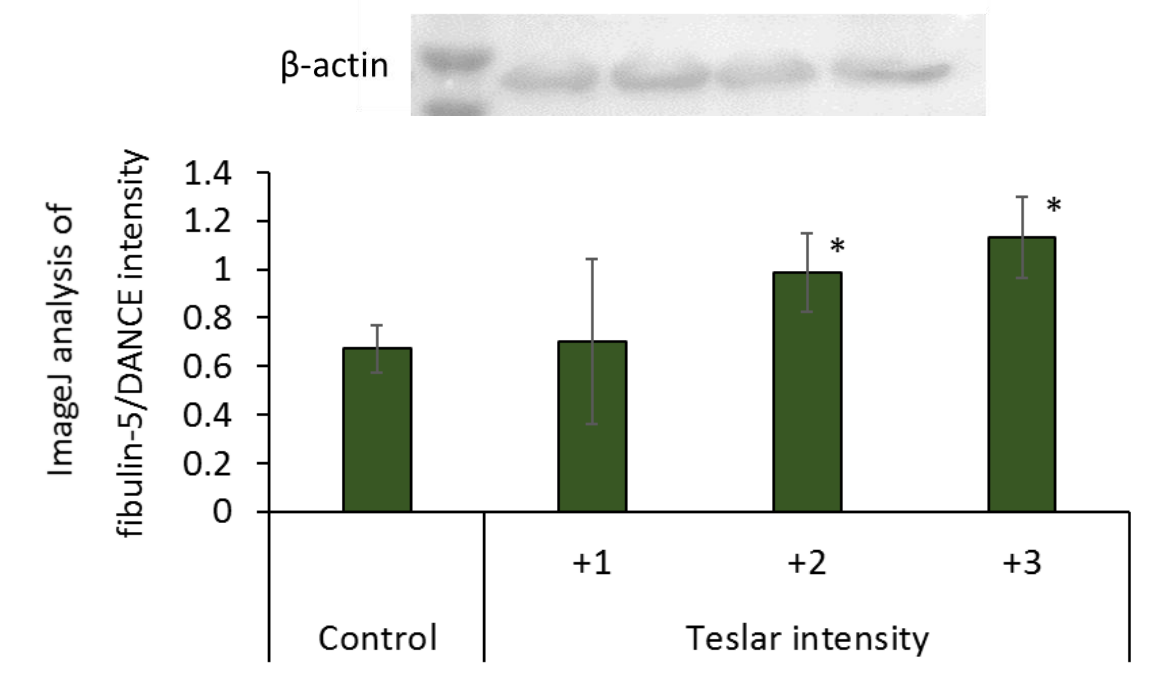

Figure 7. Effect of Teslar treatment on fibulin-5/DANCE in collagen gel-cultured human fibroblasts. (a) Western blotting of fibulin-5/DANCE in cultured human fibroblasts and (b) image analysis of fibulin-5/DANCE intensity. The results are expressed as the mean \pm standard deviation of three experiments. ${ }^{*} p<0.05$ vs. Control.

\section{Discussion}

The Teslar facial massager had a beneficial effect on skin elasticity and tended to ameliorate pore sagging. Therefore, we carried out a comprehensive gene analysis. In addition to increased ATP synthesis-related gene expression, we found increases in the expression levels of VEGFB, MCP-1, and chondroitin sulfate and fibronectin formation-related genes, followed by type I, V, XII, and XV collagen fiber formation-related genes, elastic fiber formation-related genes, and fibulin-5/DANCE (which is required for elastic fiber structure).

The dermis is the layer 1 to $2 \mathrm{~mm}$ below the surface of the skin. It is composed of an extracellular matrix with collagen fibers, elastic fibers, and proteoglycans (including hyaluronic acid and chondroitin sulfate) and confers elasticity and strength to the skin. Collagen accounts for approximately $70 \%$ of the dry weight of the dermis and is responsible for skin elasticity. Elastin, which accounts for 1 to $2 \%$ of the dermis, has a cross-linked structure and confers elasticity to the skin. Proteoglycans are gel-like proteins, with a high-water content and provide moisture to the skin. Human-derived fibroblasts showed decreased collagen and proteoglycan synthesis with aging in vitro [6,7]. Dermal fibroblasts obtained from elderly people, were reported to show reduced elastin gene expression [8]. The collagen content is reduced in aged skin [9]. Teslar treatment increased MCP-1, TGF- $\beta$, and TGFBRAP1 mRNA. MCP-1 and TGF- $\beta$, also increased type I collagen fibers and proteoglycans $[10,11]$. MCP-1 contributes to fibril formation, through TGF- $\beta$-mediated promotion of type I collagen gene expression in fibroblasts. Furthermore, TGF- $\beta$ increases type I, IV, and XV collagen, and chondroitin 6-sulfate mRNA expression [12-16]. These increases trigger TGF- $\beta$, to promote the expression of type I and XV collagen and chondroitin 6-sulfate, thus promoting fiber formation. TGF- $\beta$ is reported to 
be increased with Nd:YAG $1320 \mathrm{~nm}$ and Er:YAG $2940 \mathrm{~nm}$ mini-peel treatments but is not increased with intense pulsed light or mesotherapy treatment [17]. A cream containing TGF- $\beta$ and ascorbic acid improves the appearance of wrinkles [18]. In the comprehensive gene analysis of this study, the mRNA levels of C-C motif chemokine 2 (MCP-1) increased at $3 \mathrm{~h}$ after Teslar treatment. The mRNA levels of TGF- $\beta$, chondroitin sulfate, collagen, and elastin also increased at $48 \mathrm{~h}$ after Teslar treatment. We considered that the Teslar-induced increases in MCP-1 led to increases in TGF- $\beta$, chondroitin sulfate followed by collagen and elastin.

Fibulin-5/DANCE, binds to the elastin monomer tropoelastin, thus promoting its coacervation [19]. Tropoelastin is a secreted, 72-kDa protein with a repetitive sequence [20] that induces coacervation around temperatures, close to body temperature, and is characteristically re-solubilized with cooling. Coacervation causes both fibulin-5/DANCE and tropoelastin, to link with the lysine residues of adjacent tropoelastins with catalysis via the enzyme lysyl oxidase, producing expandable-and-contractible elastic fibers. Lysine constitutes $4 \%$ of the constituent amino acid residues in tropoelastin; however, in mature elastic fibers, almost all these residues are cross-linked. Initial linking involves mutual binding of two chemical side chains, but as the binding progresses, four chemical side chains are linked to form desmosine. Fibulin-5/DANCE, may facilitate formation of an elastic fiber structure in which the fiber components are drawn together [19]. Fibulin-5-knockout mice exhibited a phenotype with systemic elastic fiber defects, sagging skin, pulmonary emphysema, and arterial sclerosis, all of which are signs resembling human aging [21,22]. Furthermore, fibulin-5/DANCE is an essential protein produced for elastic fiber formation. Teslar treatment, elicited fibulin-5/DANCE mRNA expression and increased fibulin-5/DANCE protein levels; accordingly, we consider that increasing the fibulin-5/DANCE level, which is reduced in aging skin [5], is one aspect of the mechanism by which Teslar treatment improves skin elasticity.

The adaptor protein SARA (Smad anchor for receptor activation), presents the specific TGF- $\beta$ signal mediators (receptor-regulated SMADs (R-Smads)) Smad2 and Smad3 to the TGF- $\beta$ type 1 receptor, leading to phosphorylation of the $C$ terminal serine of R-Smad through the receptor's serine-threonine kinase activity. The phosphorylated R-Smad, forms a ternary complex with the common Smad (Common partner Smad: Co-Smad) mediator Smad4. This ternary complex migrates to the nucleus and regulates fibulin-5/DANCE gene transcription, through direct or indirect (transcription factor-mediated) binding to the specific sequence in the promoter region of that gene [23]. TGF- $\beta$ possesses serine-threonine kinase enzymatic activity that emerges as follows: The normally inactive TGF- $\beta$ type 1 receptor serine-threonine kinase, is activated by binding of the TGF- $\beta$ type 2 and type 1 receptors (transmembrane receptors on the cell membrane). TGF- $\beta$ is inactivated after binding of latency associated peptide (LAP) and ECM component latent TGF- $\beta$ binding protein (LTBP) in the extracellular matrix [24,25]. The latent form of TGF- $\beta$, is immobilized in the matrix, through the interaction of LAP and LTBP with which it is associated. LTBP-3 is reported to be reduced in aged skin [26] and binds the inactivated latent TGF- $\beta$. As a result, the inactivated TGF- $\beta$ is stored in the matrix, where it can be mobilized when required $[27,28]$. LTBP-3 mRNA level had increased with Teslar treatment, suggesting promotion of the regulatory action of TGF- $\beta$. MMP-14 mRNA level also increased with Teslar treatment. TGF- $\beta$ activity is modulated through MMP-14-dependent shedding of TGF- $\beta$-bound beta-glucan (with a co-receptor that can disrupt signal transmission after interaction with TGF- $\beta$ ) [29]. We considered that Teslar treatment controls TGF- $\beta$ activity by increasing MMP-14, and by promoting the shedding of TGF- $\beta$-bound beta-glucan. We also considered that a Teslar-induced increase in insulin-like growth factor (IGF), contributed to the beneficial effect on skin elasticity. We based this consideration, on the action of MMP-11 (Stromelysin-3) in cleaving active IGF from IGFBP-1 (Insulin-like growth factor-binding protein-1) [30], and the Teslar-induced increase in MMP-11 mRNA.

As outlined above, we considered that Teslar treatment increased MCP-1 mRNA, which was followed by an increase in TGF- $\beta 1$ mRNA, LTBP-3-driven mobilization of TGF- $\beta$, and regulation of TGF- $\beta$ activity through increased MMP-14 expression, increased chondroitin 6-sulfate and fibulin-5/DANCE, and activation of type I, IV, and XV collagen and IGF. In this study, we investigated 
the reactivity of fibroblasts when weak electricity by Teslar treatment was applied to collagen gel. From now on, it will be necessary to examine the correlation between these results and the results of electrical impulses to the skin.

\section{Conclusions}

Teslar treatment was scientifically demonstrated to improve skin elasticity with two weeks of treatment, according to comparisons between Teslar treatments and controls. Based on the GeneChip ${ }^{\circledR}$ Expression Analysis results, we consider that Teslar treatment promotes ATP synthesis in cultured fibroblasts and dermal matrix structural regeneration. In particular, we demonstrated that Teslar treatment promotes fibulin-5/DANCE mRNA expression and protein levels, which gradually decrease with aging. We consider that Teslar treatment leads to recovery of skin elasticity.

Author Contributions: K.M. designed the study and drafted the manuscript. S.K., T.S., A.Y., H.K., and S.M. performed the experiments and data analysis. All authors read and approved the final manuscript.

Funding: This research received no external funding.

Conflicts of Interest: The authors declare no conflict of interest.

\section{References}

1. Uitto, J.; Bernstein, E.F. Molecular mechanisms of cutaneous aging: connective tissue alterations in the dermis. J. Investig. Dermatol. Symp. Proc. 1998, 3, 41-44. [PubMed]

2. Hwang, K.A.; Yi, B.R.; Choi, K.C. Molecular mechanisms and in vivo mouse models of skin aging associated with dermal matrix alterations. Lab. Anim. Res. 2011, 27, 1-8. [CrossRef] [PubMed]

3. Verzijl, N.; DeGroot, J.; Thorpe, S.R.; Bank, R.A.; Shaw, J.N.; Lyons, T.J.; Bijlsma, J.J.W.; Lafeber, F.P.J.G.; Baynes, J.W.; TeKoppele, J.M. Effect of collagen turnover on the accumulation of advanced glycation end products. J. Biol. Chem. 2000, 275, 39027-39031. [CrossRef] [PubMed]

4. Shapiro, S.D.; Endicott, S.K.; Province, M.A.; Pierce, J.A.; Campbell, E.J. Marked longevity of human lung parenchymal elastic fibers deduced from prevalence of D-aspartate and nuclear weapons-related radiocarbon. J. Clin. Investig. 1991, 87, 1828-1834. [CrossRef] [PubMed]

5. Kadoya, K.; Sasaki, T.; Kostka, G.; Timpl, R.; Matsuzaki, K.; Kumagai, N.; Sakai, L.Y.; Nishiyama, T.; Amano, S. Fibulin-5 deposition in human skin: decrease with ageing and ultraviolet $\mathrm{B}$ exposure and increase in solar elastosis. Br. J. Dermatol. 2005, 153, 607-612. [CrossRef] [PubMed]

6. Hildebran, J.N.; Absher, M.; Low, R.B. Altered rates of collagen synthesis in in vitro aged human lung fibroblasts. In Vitro 1983, 19, 307-314. [CrossRef] [PubMed]

7. Matuoka, K.; Mitsui, Y. Changes in cell-surface glycosaminoglycans in human diploid fibroblasts during in vitro aging. Mech. Age. Dev. 1981, 15, 153-163. [CrossRef]

8. Fazio, M.J.; Olsen, D.R.; Kuivaniemi, H.; Chu, M.L.; Davidson, J.M.; Rosenbloom, J.; Uitto, J. Isolation and characterization of human elastin cDNAs, and age-associated variation in elastin gene expression in cultured skin fibroblasts. Lab. Investig. 1988, 58, 270-277. [PubMed]

9. Varani, J.; Dame, M.K.; Rittie, L.; Fligiel, S.E.G.; Kang, S.; Fisher, G.J.; Voorhees, J.J. Decreased collagen production in chronologically aged skin: roles of age-dependent alteration in fibroblast function and defective mechanical stimulation. Am. J. Pathol. 2006, 168, 1861-1868. [CrossRef] [PubMed]

10. Kim, M.S.; Song, H.J.; Lee, S.H.; Lee, C.K. Comparative study of various growth factors and cytokines on type I collagen and hyaluronan production in human dermal fibroblasts. J. Cosmet. Dermatol. 2014, 13, 44-51. [CrossRef] [PubMed]

11. Tiedemann, K.; Malmström, A.; Westergren-Thorsson, G. Cytokine regulation of proteoglycan production in fibroblasts: separate and synergistic effects. Matrix Biol. 1997, 15, 469-478. [CrossRef]

12. Armendariz-Borunda, J.; Katayama, K.; Seyer, J.M. Transcriptional mechanisms of type I collagen gene expression are differentially regulated by interleukin-1 beta, tumor necrosis factor alpha, and transforming growth factor beta in Ito cells. J. Biol. Chem. 1992, 267, 14316-14321. [PubMed] 
13. Grande, J.P.; Melder, D.C.; Zinsmeister, A.R. Modulation of collagen gene expression by cytokines: stimulatory effect of transforming growth factor-beta1, with divergent effects of epidermal growth factor and tumor necrosis factor-alpha on collagen type I and collagen type IV. J. Lab. Clin. Med. 1997, 130, 476-486. [CrossRef]

14. Kivirikko, S.; Mauviel, A.; Pihlajaniemi, T.; Uitto, J. Cytokine modulation of type XV collagen gene expression in human dermal fibroblast cultures. Exp. Dermatol. 1999, 8, 407-412. [CrossRef] [PubMed]

15. Schönherr, E.; Järveläinen, H.T.; Sandell, L.J.; Wight, T.N. Effects of platelet-derived growth factor and transforming growth factor-beta 1 on the synthesis of a large versican-like chondroitin sulfate proteoglycan by arterial smooth muscle cells. J. Biol. Chem. 1991, 266, 17640-17647. [PubMed]

16. Kähäri, V.M.; Larjava, H.; Uitto, J. Differential regulation of extracellular matrix proteoglycan (PG) gene expression. Transforming growth factor-beta 1 up-regulates biglycan (PGI), and versican (large fibroblast PG) but down-regulates decorin (PGII) mRNA levels in human fibroblasts in culture. J. Biol. Chem. 1991, 266, 10608-10615.

17. El-Domyati, M.; El-Ammawi, T.S.; Medhat, W.; Moawad, O.; Mahoney, M.G.; Uitto, J. Expression of transforming growth factor- $\beta$ after different non-invasive facial rejuvenation modalities. Int. J. Dermatol. 2015, 54, 396-404. [CrossRef] [PubMed]

18. Ehrlich, M.; Rao, J.; Pabby, A.; Goldman, M.P. Improvement in the appearance of wrinkles with topical transforming growth factor beta(1) and l-ascorbic acid. Dermatol. Surg. 2006, 32, 618-625. [PubMed]

19. Hirai, M.; Ohbayashi, T.; Horiguchi, M.; Okawa, K.; Hagiwara, A.; Chien, K.R.; Kita, T.; Nakamura, T. Fibulin-5/DANCE has an elastogenic organizer activity that is abrogated by proteolytic cleavage in vivo. J. Cell Biol. 2007, 176, 1061-1071. [CrossRef] [PubMed]

20. Rosenbloom, J.; Abrams, W.R.; Mecham, R. Extracellular matrix 4: the elastic fiber. FASEB J. 1993, 7, 1208-1218. [CrossRef] [PubMed]

21. Nakamura, T.; Lozano, P.R.; Ikeda, Y.; Iwanaga, Y.; Hinek, A.; Minamisawa, S.; Cheng, C.F.; Kobuke, K.; Dalton, N.; Takeda, Y.; et al. Fibulin-5/DANCE is essential for elastogenesis in vivo. Nature 2002, 415, 171-175. [CrossRef] [PubMed]

22. Yanagisawa, H.; Davis, E.C.; Starcher, B.C.; Ouchi, T.; Yanagisawa, M.; Richardson, J.A.; Olson, E.N. Fibulin-5 is an elastin-binding protein essential for elastic fibre development in vivo. Nature 2002, 415, 168-171. [CrossRef] [PubMed]

23. Kuang, P.P.; Joyce-Brady, M.; Zhang, X.H.; Jean, J.C.; Goldstein, R.H. Fibulin-5 gene expression in human lung fibroblasts is regulated by TGF-beta and phosphatidylinositol 3-kinase activity. Am. J. Physiol. Cell Physiol. 2006, 291, C1412-C1421. [CrossRef] [PubMed]

24. Taipale, J.; Saharinen, J.; Hedman, K.; Keski-Oja, J. Latent transforming growth factor-beta 1 and its binding protein are components of extracellular matrix microfibrils. J. Histochem. Cytochem. 1996, 44, 875-889. [CrossRef] [PubMed]

25. Taipale, J.; Miyazono, K.; Heldin, C.H.; Keski-Oja, J. Latent transforming growth factor-beta 1 associates to fibroblast extracellular matrix via latent TGF-beta binding protein. J. Cell Biol. 1994, 124, 171-181. [CrossRef] [PubMed]

26. Langton, A.K.; Sherratt, M.J.; Griffiths, C.E.; Watson, R.E. Differential expression of elastic fibre components in intrinsically aged skin. Biogerontology 2012, 13, 37-48. [CrossRef] [PubMed]

27. Saharinen, J.; Keski-Oja, J. Specific sequence motif of 8-Cys repeats of TGF-beta binding proteins, LTBPs, creates a hydrophobic interaction surface for binding of small latent TGF-beta. Mol. Biol. Cell 2000, 11, 2691-2704. [CrossRef] [PubMed]

28. Robertson, I.B.; Horiguchi, M.; Zilberberg, L.; Dabovic, B.; Hadjiolova, K.; Rifkin, D.B. Latent TGF- $\beta$-binding proteins. Matrix Biol. 2015, 47, 44-53. [CrossRef] [PubMed]

29. Velasco-Loyden, G.; Arribas, J.; Lopez-Casillas, F. The shedding of betaglycan is regulated by pervanadate and mediated by membrane type matrix metalloprotease-1. J. Biol. Chem. 2004, 279, 7721-7733. [CrossRef] [PubMed]

30. Manes, S.; Mira, E.; Barbacid, M.M.; Cipres, A.; Fernandez-Resa, P.; Buesa, J.A.; Merida, I.; Aracil, M.; Marquez, G.; Martinez-A, C. Identification of insulin-like growth factor-binding protein-1 as a potential physiological substrate for human stromelysin-3. J. Biol. Chem. 1997, 272, 25706-25712. [CrossRef] [PubMed]

(C) 2018 by the authors. Licensee MDPI, Basel, Switzerland. This article is an open access article distributed under the terms and conditions of the Creative Commons Attribution (CC BY) license (http:/ / creativecommons.org/licenses/by/4.0/). 